\title{
Conventional and Laparoscopic Reversal of the Hartmann Procedure: a Review of Literature
}

\author{
Bryan Joost Marinus van de Wall • \\ Werner A. Draaisma • Esther S. Schouten • \\ Ivo A. M. J. Broeders • Esther C. J. Consten
}

Received: 1 August 2009 /Accepted: 26 October 2009/Published online: 21 November 2009

(C) The Author(s) 2009. This article is published with open access at Springerlink.com

\begin{abstract}
Purpose The aim of this study was to provide a systematic overview on both laparoscopic and conventional Hartmann reversal. Furthermore, the Hartmann procedure is reevaluated in the light of new emerging alternatives.

Methods Medline, Ovid, EMBASE, and Cochrane database were searched for studies reporting on outcomes after Hartmann reversal.

Results Thirty-five studies were included in this review of which 30 were retrospective. A total of 6,249 patients with a mean age of 60 years underwent Hartmann reversal. Two thirds of patients were classified as American Society of Anesthesiologists (ASA) I-II. The mean reversal rate after a Hartmann procedure was 44\%, and mean time interval between Hartmann procedure and Hartmann reversal was 7.5 months. The most frequent reported reasons for renouncing Hartmann reversal were high ASA classification and patients' refusal. The overall morbidity rate ranged from 3\% to 50\% (mean $16.3 \%$ ) and mortality rate from $0 \%$ to $7.1 \%$ (mean 1\%). Patients treated laparoscopically had a shorter hospital stay (6.9 vs. 10.7 days) and appeared to have lower mean morbidity rates compared to conventional surgery (12.2\% vs. $20.3 \%)$.

Conclusion Hartmann reversal carries a high risk on perioperative morbidity and mortality. The mean reversal rate is considerably low (44\%). Laparoscopic reversal compares favorably to conventional; however, high level evidence is needed to determine whether it is superior.
\end{abstract}

Keywords Hartmann $\cdot$ Reversal $\cdot$ Morbidity $\cdot$ Mortality

BJM and ESS performed the systematic review and drafted the manuscript. WAD coauthored the writing of the manuscript. ECJC and IAMJB also coauthored the writing and have given final approval of the version to be published.

B. J. M. van de Wall • W. A. Draaisma • E. S. Schouten •

I. A. M. J. Broeders $\cdot$ E. C. J. Consten

Department of Surgery, Meander Medical Center,

Utrechtseweg 160 ,

3818 ES Amersfoort, The Netherlands

E. C. J. Consten $(\square)$

Department of Surgery, Meander Medical Center Amersfoort, Postbus 1502, 3800 BM Amersfoort, The Netherlands

e-mail: ecj.consten@meandermc.nl

\section{Introduction}

The Hartmann procedure (HP) consists of a sigmoidectomy with rectal stump closure and a terminal colostomy. It is a common operation for left-sided colonic disease, especially in emergency cases. Initially, this procedure was solely performed in cases of neoplastic obstructions. Currently, indications include complicated diverticulitis, traumatic lesions, and perforated tumors of the rectosigmoid and volvulus. ${ }^{1}$

The Hartmann procedure was initially designed to reduce mortality caused by anastomotic dehiscence. However, reestablishing continuity after a Hartmann procedure (Hartmann reversal, HR) is still considered a major surgical procedure and carries serious risk of surgical morbidity and mortality of up to $50 \%$ and $5 \%$, respectively, in the published literature. ${ }^{2,3}$ Several attempts have been under- 
taken to perform HR by minimally invasive techniques with the objective to reduce high morbidity and mortality rates. Nevertheless, it has been estimated that approximately half of patients who undergo a Hartmann procedure will not have continuity restored by either a minimally invasive or open technique., ${ }^{4,5}$

Many studies on HR have been published. However, due to the large amount of studies on this subject, it is difficult to determine the characteristics and percentage of patients who undergo reversal and morbidity and mortality rates after both laparoscopic and conventional HR. Furthermore, the HR must be reevaluated in the light of new emerging alternatives. This study provides a systematic overview of the available current evidence to evaluate the aforementioned topics and put the HR in perspective of innovative alternatives.

\section{Material and Methods}

\section{Literature Search}

A systematic search of the literature was conducted to identify all studies on the reversal of the Hartmann procedure. We performed a duplicate search of the electronic databases PubMed, EMBASE, and the Cochrane library (from October 1987 until May 2009) using the following keywords and text word terms: "Hartmann", "Hartman", "Hartman's", "Hartmann's", "anastomosis", "reconstruction", "reversal", "continuity", and "restoration". The "related articles" function in PubMed was also used to identify additional studies. References of the articles identified were also searched for by title and then subsequent abstract review.

\section{Study Selection}

Studies were selected according to the following selection criteria: (1) study is about reversal of Hartmann procedure, (2) publication is not an expert opinion or case report, (3) English language publication, and (4) more than ten patients included. The methodological quality of the included studies was judged in terms of the grades of evidence according to the Oxford Centre for Evidencebased Medicine Levels of Evidence. The methodological quality of the studies was judged independently by two reviewers (BJM and/or ES). Discrepancies between reviewers were resolved by discussion by a senior coauthor (WA).

\section{Data Extraction}

Patient-related data (indication of initial Hartmann procedure, age, gender, American Society of Anesthesiologists (ASA) classification), operative and hospital-related data such as the number of Hartmann procedures and reversals, reversal rate, reasons not to perform reversal, time interval between Hartmann procedure and reversal, hospital stay, morbidity (bleeding, wound infection, anastomosis leakage or stricture, and cardiac or pulmonary complications), mortality, operative time of both conventional and/or laparoscopic reversal, conversion rates, and reasons for conversion were gathered and analyzed. The ASA scores were divided in three groups: groups I-II, group III, and groups IV-V. ASA scores I-II represent healthy patients or with mild systemic disease. ASA III represents patients with moderate to severe systemic disease, and ASA IV-V represent patients with severe to life-threatening systemic disease.

\section{Data Analysis and Presentation}

Data analysis was limited to basic manipulation because of a lack of statistically relevant data, resulting from large trials. Descriptive statistics including means, counts, and percentages were used to describe the study population for all variables.

\section{Results}

\section{Baseline and Patient Characteristics}

The search initially yielded 813 articles (Fig. 1). After screening of title and abstract, 747 articles were excluded because they were not about HR. Sixty-six manuscripts were screened using the inclusion criteria. A total of 31 publications were excluded because they were not about HR (19 articles), included less than ten patients (ten articles), and were not about humans or in English (two articles) leaving 36 studies to be included in this review. ${ }^{1-35}$

In Table 1, the authors, year of publication, level of evidence, number of patients who underwent reversal, operative indication, ASA classification, age, and gender are presented. The year of publication ranged from 1987 to 2009. Five studies were prospective and 30 were retrospective. ${ }^{6}$ The size of the individual study population ranged from 12 to 3,051 (mean 179) patients. The overall female-male ratio was $1: 1.14$ and the mean age was 60 years (38-71).

The indication for Hartmann procedure varied among studies. Diverticular disease and its associated complications (mostly fecal and purulent peritonitis followed by abscess, obstruction, and fistula) were the most common indication for Hartmann procedure in $67 \%$ of patients. Five studies included patients with diverticular disease only, with fecal and purulent peritonitis also being the most frequent indication for the initial procedure. ${ }^{3}$ Colorectal malignancies causing obstruction or perforation were found 
Figure 1 Flowchart describing the selection of studies included in this review.

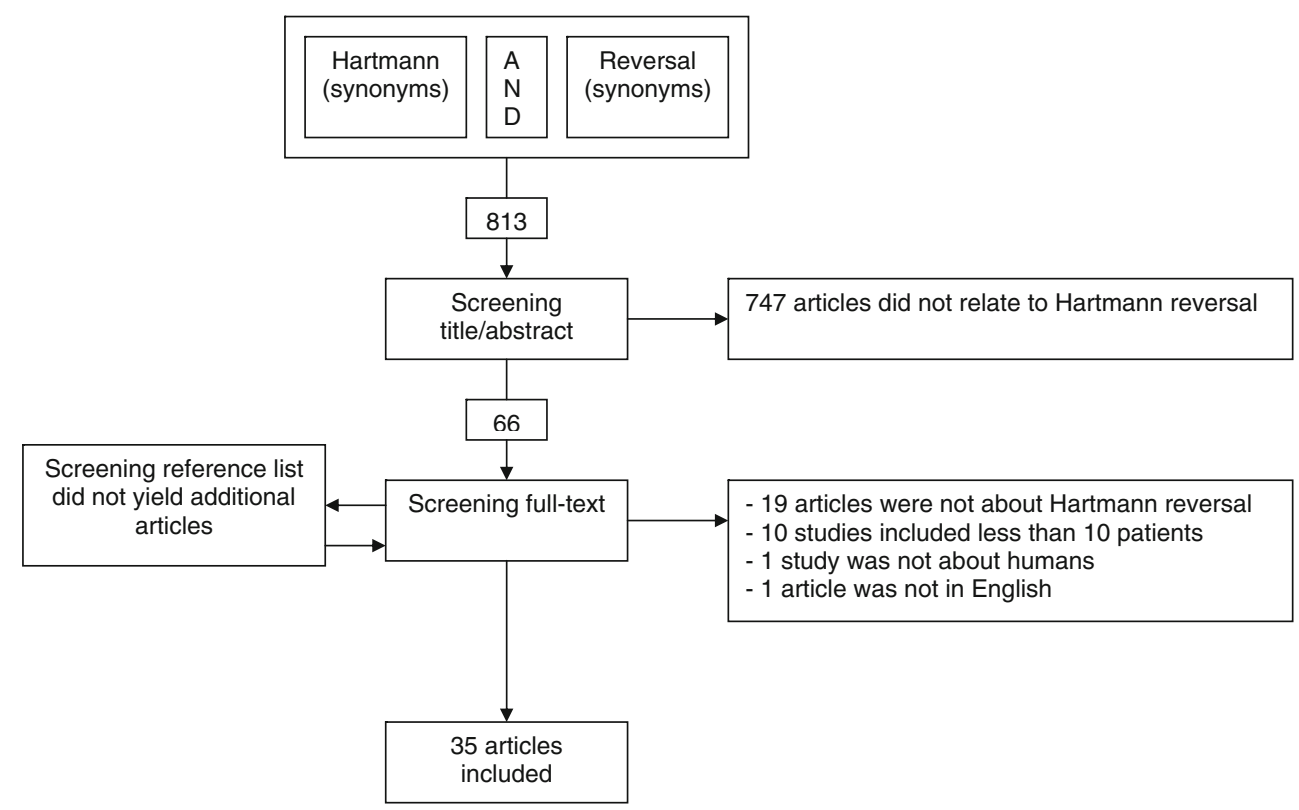

to be the indication in $17 \%$ of patients. Other indications including inflammatory bowel disease, ischemia, volvulus, (iatrogenic) trauma, perforation, and anastomosis leakage following resection with primary anastomosis comprised $16 \%$ of cases.

Of the 646 patients who underwent reversal in these studies, 433 patients $(67 \%)$ were considered relatively healthy (ASA I and II). For moderately healthy patients (ASA III), this amount was 200 patients (31\%). A fraction of patients that underwent reversal was considered ASA IV $(2 \%) .^{3,9,12,21,24}$ Reasons for performing reversal in this high risk group were not reported. Only two studies reported both the ASA classification of patients who underwent reversal and those that did not. Roque-Castellano et al. studied a population consisting of 162 patients that had an initial Hartmann procedure. ${ }^{1}$ Of this group, 63 patients were considered ASA I or II, 72 patients ASA III, and 27 were considered ASA IV. Only 32 out of the 63 ASA I/II patients $(51 \%)$ underwent reversal as shown in Fig. 2. For the ASA III patients, this amount was nine out of $72(13 \%)$, and for ASA IV, one out of 27 patients (4\%). Banerjee et al. reported that three out of 25 ASA IV patients (12\%) underwent reversal. ${ }^{18}$ The percentages of other ASA classifications were not reported.

\section{Morbidity and Mortality of Hartmann Reversal}

In Table 2 and Table 3, the hospital stay and morbidity and mortality rates after conventional and laparoscopic HR are presented. The overall morbidity rate of the HR (conventional plus laparoscopic approach) is considerably high ranging from $3.6 \%$ to $50 \%$ (mean $16.3 \%$ ). The most frequent postoperative complication was wound infection which ranged from $5 \%$ to $30 \%$ (mean $12.5 \%$ ). ${ }^{18}$ Other common postoperative complications include cardiopulmonary complications ranging from $1 \%$ to $14.6 \%$ (mean $5.3 \%$ ) followed by anastomosis leakage with a range of $0 \%$ to $16 \%$ (mean 5.2\%) and postoperative bleeding from wound or anastomosis site ranging from $0 \%$ to $7 \%$ (mean $3.2 \%$ ). Late complications including anastomosis stricture ranged from $2 \%$ to $10 \%$ (mean $5.8 \%$ ).

Mainly because of anastomosis-related complications (leakage and stricture), between $0 \%$ and 20\% (mean 5.3\%) of evaluated patients required secondary surgery after reversal of HP. Of the patients that required a reoperation, $24 \%$ to $50 \%$ were left with a permanent stoma. ${ }^{11,14,15,19,22,28-32}$ This proportion comprises $3 \%$ to $12.5 \%$ (mean $6.1 \%$ ) of all patients that underwent HR.

Mortality was largely caused by septic complications due to anastomotic dehiscence or postoperative abscesses. ${ }^{2,5,7,8,10,12,13,15,18-22,24-26,28,29,31-33}$ Some studies also reported renal failure and myocardial infarction after reoperation for wound dehiscence and dissipated malignancies as cause of death. ${ }^{5,8-10,13}$

\section{Laparoscopic vs. Conventional Reversal of HP}

Five studies compared laparoscopic surgery with the open approach of HR. ${ }^{10,13}$ Seven studies were solely about laparoscopic HR. ${ }^{4,11,21,25,29,31,32}$ A total of 396 patients had a laparoscopic HR vs. 5,853 patients with conventional HR.

Hospital stay appeared to be notably shorter after laparoscopic HR (mean 6.9, range 3-11 days) compared to conventional HR (mean 10.7, range 3- 
Table 1 Baseline and Patient Characteristics of Included Studies

\begin{tabular}{|c|c|c|c|c|c|c|c|c|c|c|c|c|}
\hline \multirow[t]{2}{*}{ Reference } & \multirow[t]{2}{*}{ Year } & \multirow[t]{2}{*}{ Level } & \multirow{2}{*}{$\begin{array}{l}\text { Reversal } \\
\text { ( } n \text { patients) }\end{array}$} & \multirow{2}{*}{$\begin{array}{l}\text { Age } \\
\text { (years) }\end{array}$} & \multicolumn{2}{|l|}{ Gender } & \multicolumn{3}{|c|}{ Initial indication } & \multicolumn{3}{|c|}{ ASA classification } \\
\hline & & & & & Female $(n)$ & Male $(n)$ & Div (\%) & CA $(\%)$ & Other (\%) & $\begin{array}{l}\text { ASA I- } \\
\text { II }(\%)\end{array}$ & ASA III (\%) & $\begin{array}{l}\text { ASA IV- } \\
\text { V }(\%)\end{array}$ \\
\hline $\begin{array}{l}\text { Sweeney and } \\
\text { Hoffmann }\end{array}$ & 1987 & IV & 19 & 71 & 10 & 9 & 100 & 0 & 0 & - & - & - \\
\hline Basse & 1991 & $\mathrm{IIb}$ & 27 & 50 & 14 & 13 & 50 & 22 & 28 & - & - & - \\
\hline Roe & 1991 & IV & 69 & 67 & 38 & 31 & 70 & 30 & 0 & - & - & - \\
\hline $\begin{array}{l}\text { Geoghegan and } \\
\text { Rosenberg }\end{array}$ & 1991 & IV & 55 & 65 & - & - & 58 & 31 & 11 & 90 & 10 & 0 \\
\hline Pearce & 1992 & IV & 80 & 65 & 44 & 36 & 71 & 24 & 5 & - & - & - \\
\hline Keck & 1993 & IV & 50 & - & - & - & 80 & 14 & 6 & - & - & - \\
\hline Sosa ${ }^{b}$ & 1994 & IV & 18 & 38 & 4 & 14 & 50 & 0 & 50 & - & - & - \\
\hline Khan & 1994 & IV & 28 & 58 & 13 & 15 & 100 & 0 & 0 & - & - & - \\
\hline Wigmore & 1995 & IV & 178 & 65 & 93 & 85 & 63 & 33 & 4 & - & - & - \\
\hline Macpherson $^{\mathrm{b}}$ & 1996 & IV & 12 & 62 & 7 & 5 & 75 & 17 & 8 & - & - & - \\
\hline Regadas $^{\mathrm{b}}$ & 1996 & IV & 20 & 52.8 & 10 & 10 & 10 & 20 & 70 & - & - & - \\
\hline Carcoforo $^{\mathrm{a}}$ & 1996 & IV & 19 & - & 9 & 10 & - & - & - & - & - & - \\
\hline Seetharam & 2003 & IV & 23 & - & - & - & 84 & 8 & 8 & - & - & - \\
\hline Maggard & 2004 & $\mathrm{IIb}$ & 765 & - & - & - & - & - & - & - & - & - \\
\hline Banerjee & 2004 & IV & 66 & 59 & 30 & 36 & - & - & - & 71 & 25 & 4 \\
\hline Rosen $^{\mathrm{b}}$ & 2005 & IV & 22 & 54 & 12 & 10 & 68 & 9 & 23 & - & - & - \\
\hline Albarran & 2004 & IV & 40 & 60 & 19 & 21 & 55 & 28 & 17 & 63 & 32 & 5 \\
\hline Bell & 2005 & IV & 20 & 56 & 1 & 19 & 55 & 20 & 25 & - & - & - \\
\hline $\operatorname{Aydin}^{\mathrm{a}}$ & 2005 & IV & 121 & 57 & 54 & 67 & 100 & 0 & 0 & 41 & 56 & 3 \\
\hline Khaikin $^{\mathrm{b}}$ & 2007 & IV & 27 & - & 10 & 17 & 70 & 19 & 11 & 56 & 44 & 0 \\
\hline Salem and Flum & 2004 & IV & 3,051 & - & - & - & - & - & - & - & - & - \\
\hline Oomen & 2005 & $\mathrm{IIb}$ & 65 & 63 & 32 & 33 & 100 & 0 & 0 & - & - & - \\
\hline Roque-Castellano & 2007 & IV & 42 & 56 & 7 & 35 & - & - & - & 77 & 21 & 2 \\
\hline Faure $^{\mathrm{a}}$ & 2007 & $\mathrm{IIb}$ & 34 & 62 & 18 & 16 & 67 & 26 & 7 & 76 & 24 & 0 \\
\hline Boland & 2007 & IV & 39 & 53.4 & 17 & 22 & 56 & 15 & 29 & - & - & - \\
\hline Schmelzer & 2007 & IV & 113 & 49.5 & 41 & 72 & 38 & 15 & 48 & 61 & 39 & 0 \\
\hline Carus $^{\mathrm{b}}$ & 2008 & IV & 28 & - & - & - & - & - & - & - & - & - \\
\hline Haughn $^{\mathrm{a}}$ & 2008 & IV & 122 & 59 & 68 & 54 & 70.5 & 18 & 11.5 & - & - & - \\
\hline Leong & 2008 & IV & 28 & - & - & - & 29 & 46 & 25 & - & - & - \\
\hline Mazeh & 2009 & IV & 82 & 60.5 & 41 & 41 & 58 & 6.1 & 35.9 & - & - & - \\
\hline Petersen $^{\mathrm{b}}$ & 2009 & $\mathrm{IIb}$ & 71 & - & 32 & 39 & - & - & - & - & - & - \\
\hline Slawik and Dixon ${ }^{b}$ & 2008 & IV & 28 & 66 & 17 & 11 & 67.9 & 25 & 8.1 & 68 & 32 & 0 \\
\hline Vermeulen $^{\mathrm{a}}$ & 2008 & IV & 63 & 61 & 26 & 35 & 100 & 0 & 0 & 63 & 23 & - \\
\hline Chouillard & 2008 & IV & 88 & 57 & 50 & 38 & 75 & 18 & 7 & - & - & - \\
\hline David & 2009 & IV & 736 & 60 & 335 & 401 & 82.6 & 17.4 & 0 & - & - & - \\
\hline Total & & & 6,249 & & 1,052 & 1,195 & - & - & - & - & - & - \\
\hline Mean & - & - & 179 & 60 & 38 & 43 & 67 & 17 & 16 & 67 & 31 & 2 \\
\hline
\end{tabular}

Div diverticulitis, $C A$ carcinoma

${ }^{a}$ Results of laparoscopic and conventional Hartmann reversal grouped together (conventional > laparoscopic)

${ }^{\mathrm{b}}$ Results of laparoscopic Hartmann reversal only

18 days). ${ }^{14,15,19,22,28,30,34}$ Furthermore, patients treated laparoscopically appeared to have a reduced mean overall morbidity rate (12.2\% vs. $20.3 \%)$. This was mainly found for wound infection (mean $10.8 \%$ vs. 14.2\%), anastomotic leakage (mean $1.2 \%$ vs. $5.1 \%$ ), and cardiopulmonary complications (mean $3.6 \%$ vs. $6.9 \%$ ). Reoperations occurred more often in conventional HR (mean $3.6 \%$ vs. $6.9 \%$ ). The need for a permanent stoma was not reported for laparoscopic HR. 
Reversal rate per ASA classification

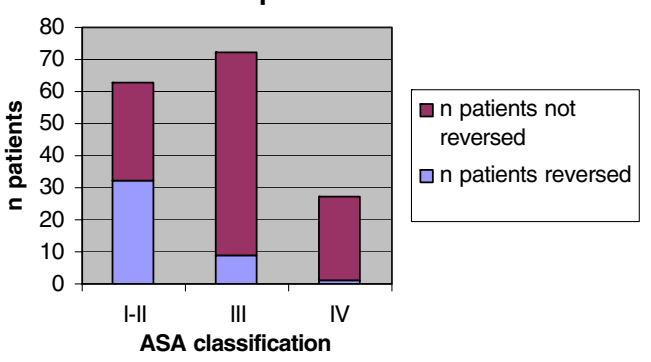

Figure 2 Reversal rate per ASA classification.

However, this percentage was on average $6.1 \%$ in the conventional group.

Mortality appeared to be comparable for both techniques (mean $0.9 \%$ vs. $1.1 \%$ ). One study reported a mortality rate of $7 \%$ in a study population of 28 patients that were treated laparoscopically. 1,6-13,20,23,25,26,27,31,32,35 In this study, one patient died from a mesenteric embolus secondary to atrial fibrillation, and one patient died from anticoagulation induced hemorrhage.

The operating time was appeared to be comparable for laparoscopic (mean $153 \mathrm{~min}$, range 30-356) and conventional HR (mean $170 \mathrm{~min}$, range 57-500). Conversion from laparoscopy to conventional surgery ranged from $7 \%$ to $22 \%$ (mean 12.6\%). Reasons for conversion were lack of visualization due to dense adhesions (80\%), rectal stump perforation $(7 \%)$, persisting infection of the rectal stump $(5 \%)$, extensive neoplasm invasion (3\%), and lesions to the bladder or spleen $(5 \%) .{ }^{30}$ Other intraoperative complications not requiring conversion included splenic lesions (4.5\%), accidental enterotomy during adhesiolysis (2.8\%), incomplete anastomosis $(2.5 \%)$, and bladder or ureteral injury.

When comparing the group of patients treated laparoscopically to the group treated conventionally, patients treated laparoscopically appeared to be slightly younger (55 vs. 61 years) and were more often initially treated for other indications (32\% vs. $13 \%$ ), such as inflammatory bowel disease, ischemia, volvulus, and trauma rather than diverticulitis $(55 \%$ vs. $67 \%)$ or malignancies $(15 \%$ vs. 19\%). Furthermore, the mean interval between Hartmann procedure and reversal was considerably shorter for patients treated laparoscopically (5.5 vs. 8.8 months). There were no apparent differences in ASA classification.

\section{Reversal Rate and Factors}

Nineteen studies mentioned the amount of patients who initially received a Hartmann procedure and therefore offered the opportunity to calculate the reversal rate (Table 4). A total of 12,302 patients had a Hartmann procedure of which 5,405 subsequently underwent reversal leading to a mean reversal rate of $44 \%$ (range $19 \%$ to $71 \%$ ). Fourteen studies mentioned reasons or factors that possibly influenced the choice not to perform a HR. The most frequent reported reason or factor was a high ASA classification mentioned in 12 studies, followed by patient refusal in nine, metastatic disease in seven, and high age in five studies. Three studies reported other reasons which mostly concerned the inability to perform an anastomosis due to persisting rectal stump difficulties. Roque-Castellano et al. published a study focusing specifically on factors related to the decision of restoring intestinal continuity after Hartmann procedure. ${ }^{1}$ They found that reestablishment of intestinal continuity was related in a statistically significant matter to male sex, nonneoplastic disorder, younger age, and lower ASA classification. Other studies also supported the fact that high age and ASA classification are associated with a low reversal rate. ${ }^{1}$

The interval between the original Hartmann procedure and its reversal varied widely between studies as demonstrated in Table 5. Two studies included patients who underwent their reversal after an interval shorter than 3 months. ${ }^{13,28}$ These studies had comparable outcomes with studies that had a longer time interval. The longest interval reported was 13.5 months and was attributed to a long waiting list in the concerning hospital. ${ }^{1}$ The mean interval of all included studies was 6.7 months. Approximately $7 \%$ to $16 \%$ of patients waiting for reversal died due to diseaserelated complications (mostly metastatic disease). ${ }^{30}$

\section{Discussion}

With this systematic review, we have attempted to summarize all evidence currently available in the literature concerning the indications of HP and the number and characteristics of patients who undergo reversal of this procedure with its morbidity and mortality. Although at this point in time high level studies are lacking, this study indicates that the initial HP is mainly reserved for patients with complicated (Hinchey III-IV) diverticulitis and patients with fecal or purulent peritonitis due to tumor perforation. Approximately $44 \%$ of patients undergo bowel continuity restoration after HP with a mean interval of 7.5 months. The majority of patients (mean age 60 years) undergoing reversal are considered ASA I-II. Reversal of HP is accompanied by a considerable risk of complications (mean 16.3\%, range $3-50 \%)$ and has an overall mortality rate of $1 \%$. When comparing the few studies on laparoscopic HR with conventional surgery, a lower overall morbidity rate is found $(12.2 \%$ vs. $20.3 \%$ ). Furthermore, patients treated laparoscopically have a shorter hospital time compared to conventional reversal (6.9 vs. 10.7 days). Mortality, however, is comparable for both operative techniques. 


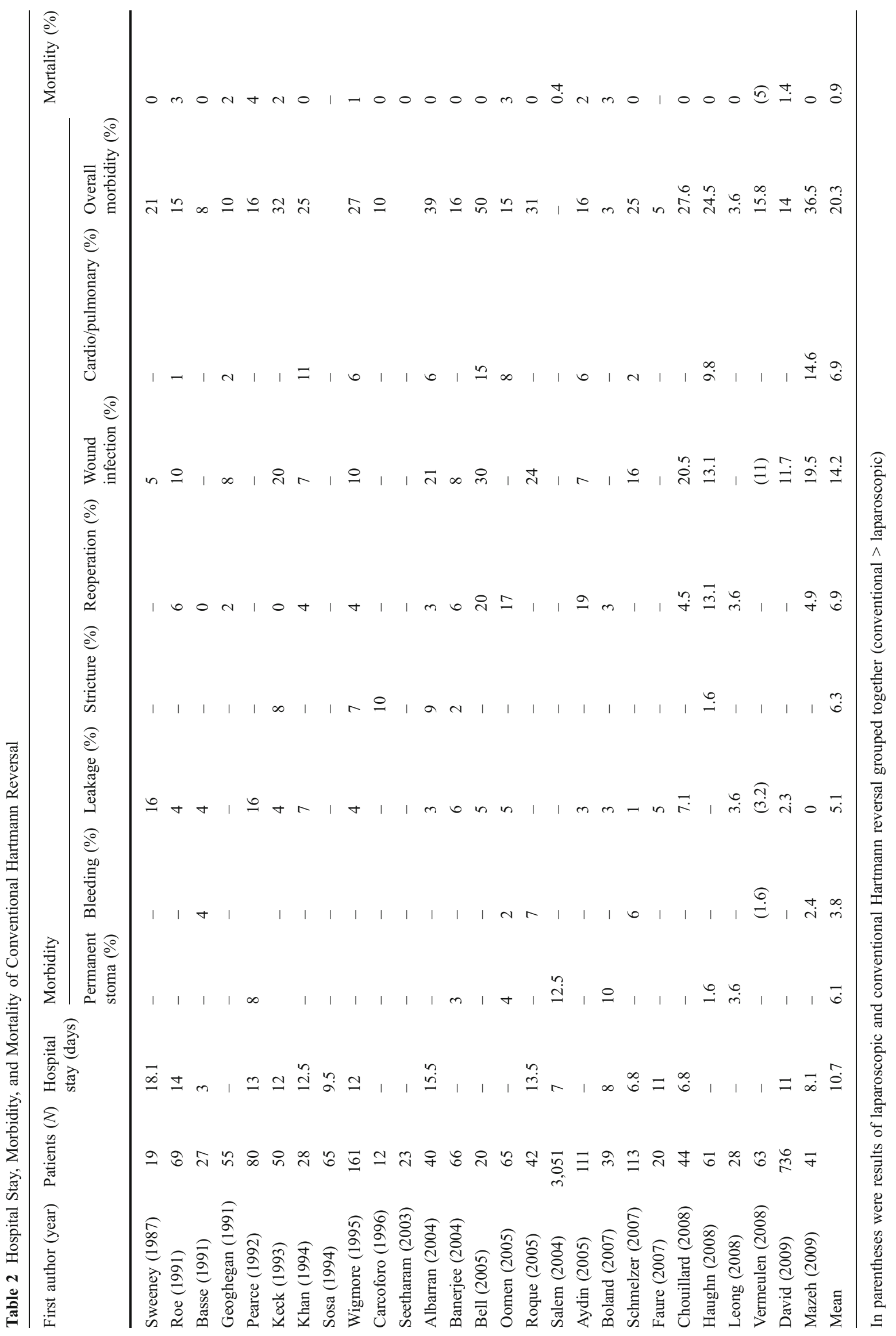




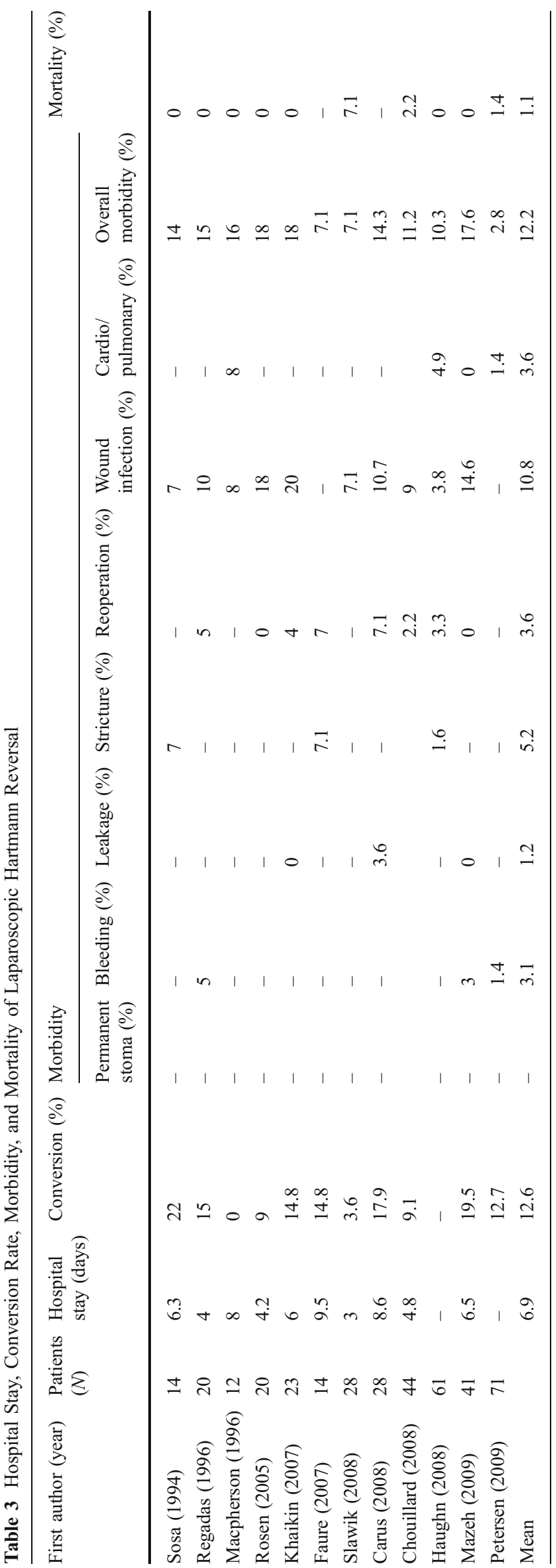

ASA classification and high age are frequently reported as a reason to abstain from reversal. Although this review was not constructed to address this issue, it is generally thought that these factors are associated with higher morbidity and mortality rates. ${ }^{16,18,33}$ Unfortunately, the majority of patients with a colostomy after HP are old and considered ASA III or higher. Therefore, a large group of patients are left with a permanent stoma mainly because reversal is considered risk full due to their fragile state of health. Such a group of patients may benefit from less invasive procedures.

Laparoscopic HR seems to be a promising alternative to open surgery. By reducing the invasiveness of the operation, this review has found decreased postoperative recovery time. Furthermore, the mean overall morbidity rate appears to be reduced for laparoscopic HR. However, there is considerable overlap in range between laparoscopic and conventional HR (2.8-17.6\% vs. $3-50 \%)$. Conversion rates, ranging from $0 \%$ to $22 \%$, reflect the fact that the operation is technically demanding and might also result in elevated morbidity rates. Laparoscopic reversal is a relatively new technique with only small numbers of retrospective case series each containing no more than seven to 71 patients. It is therefore uncertain what the effects of selection bias are on the outcomes after laparoscopic HR. Randomized trials are necessary to determine whether laparoscopic reversal is indeed superior to the conventional technique.

HP has been the operation of choice for complicated diverticulitis and tumor perforation with peritonitis. HP was recommended because it could potentially avoid intraabdominal sepsis related to anastomotic leakage. However, several studies have demonstrated that primary anastomosis with or without defunctioning ileo- or colostomy after resection could safely be performed in patients with peritonitis and eliminate the need for an invasive second stage reversal. In a recent review, the leak rate of the primary anastomosis was described at $5.5 \%$ which compared favorably with the leak rate found in our review after HR (mean 3.2\%, range $0-16 \%$ ). ${ }^{18,20}$ However, certain considerations must be taken into account. Firstly, most studies comparing the Hartmann procedure with primary anastomosis with or without defunctioning colo- or ileostomy are retrospective with inherent selection bias. Patients that undergo HP often suffer from more extensive disease when compared to patients who have primary anastomosis. Therefore, solid conclusions cannot sufficiently be drawn regarding this topic, and it therefore may be justified that the choice of operative technique should be considered on an individual basis. In The Netherlands, a trial has been developed to address this issue in the near future. Secondly, reversal of the ileo- and colostomies carry considerable morbidity themselves ranging from $4.6 \%$ to $34 \%$ with anastomotic leakage occurring in $0-2.2 \%$ of patients. ${ }^{36}$ 
Table 4 Reversal Rate and Reasons for Not Performing Reversal

First author (year) Patients HP (n) Patients HR (n) Reversal rate (\%) Reasons for not performing reversal

High ASA Patient refusal Metastatic disease High age Other

\begin{tabular}{|c|c|c|c|c|c|c|c|c|}
\hline Sweeney 1987) & 30 & 19 & 63 & $X$ & $\mathrm{X}$ & & & \\
\hline Roe (1991) & 107 & 69 & 64 & $\mathrm{X}$ & $\mathrm{X}$ & $\mathrm{X}$ & & \\
\hline Geoghegan (1991) & 108 & 55 & 51 & $X$ & $\mathrm{X}$ & $\mathrm{X}$ & & $\mathrm{X}$ \\
\hline Pearce (1992) & 145 & 80 & 55 & & & & & \\
\hline Keck (1993) & 111 & 50 & 45 & $\mathrm{X}$ & $\mathrm{X}$ & $\mathrm{X}$ & & $\mathrm{X}$ \\
\hline Khan (1994) & 61 & 28 & 46 & $\mathrm{X}$ & $\mathrm{X}$ & $\mathrm{X}$ & & \\
\hline Wigmore (1995) & 345 & 178 & 47 & & & & & \\
\hline Carcoforo $^{a}$ (1996) & 43 & 19 & 44 & & & & & \\
\hline Seetharam (2003) & 124 & 23 & 19 & & & & & \\
\hline Banerjee (2004) & 110 & 66 & 61 & $\mathrm{X}$ & & & $\mathrm{X}$ & \\
\hline Albarran (2004) & 74 & 40 & 54 & & $\mathrm{X}$ & & & \\
\hline Maggard (2004) & 1,176 & 765 & 65 & $\mathrm{X}$ & & & $\mathrm{X}$ & \\
\hline Salem (2004) & 5,420 & 3,051 & 56 & & & & $\mathrm{X}$ & \\
\hline Oomen (2005) & 91 & 65 & 71 & $X$ & & & & \\
\hline Roque (2007) & 164 & 42 & 30 & $\mathrm{X}$ & & $\mathrm{X}$ & $\mathrm{X}$ & \\
\hline Leong (2008) & 70 & 28 & 40 & $\mathrm{X}$ & $\mathrm{X}$ & $\mathrm{X}$ & & \\
\hline Vermeulen (2008) & 139 & 63 & 45 & $X$ & $\mathrm{X}$ & $\mathrm{X}$ & $\mathrm{X}$ & $\mathrm{X}$ \\
\hline Carus $^{\mathrm{b}}$ (2008) & 34 & 28 & 82 & $\mathrm{X}$ & $\mathrm{X}$ & & & \\
\hline David (2009) & 3,950 & 736 & 23.3 & & & & & \\
\hline Mean & 647 & 284 & 44 & - & - & - & - & - \\
\hline
\end{tabular}

${ }^{\text {a }}$ Results of laparoscopic and conventional Hartmann reversal grouped together

${ }^{\mathrm{b}}$ Studies reporting results of laparoscopic Hartmann reversal only

Moreover, $0-16.7 \%$ of colo- and ileostoma are never reversed (reasons are patient refusal, general inoperability, tumor progression, and anal sphincter insufficiency). ${ }^{37-40}$ Noteworthy, however, this compares favorably to the reversal rate of $44 \%$ after the Hartmann procedure.

This review has several limitations. The analysis of data mainly serves as descriptive purposes identifying characteristics of patients undergoing HR, reversal rates, reasons not to reverse, and morbidity and mortality of laparoscopic and conventional HR. It does not intend to provide direct comparison between laparoscopic HR and conventional HR. Therefore, certain considerations must be taken into account when attempting to compare laparoscopic to conventional HR using results of this review. Firstly, the decision on surgical approach in the studies was based on surgeon's preferences leading to certain amounts of selection bias. Predominantly, the interval between Hartmann procedure and reversal was significantly lower in patients treated laparoscopically. It is difficult to evaluate to what extent this may have biased the results as it remains a controversial topic in the literature. Secondly, a serious confounder could be the moment of publication; studies on laparoscopic surgery were published since 1996, while studies on open reversal were published since 1987. As recent developments have led to shorter hospitalization times in general, more recent publications, such as studies on laparoscopic HR, might report shorter hospital stay compared to older publications such as studies on conventional HR. To date, clear comparison is nearly impossible as studies that attempted to compare laparoscopic HR to conventional HR are retrospective and not randomized.

Recently, an innovative promising technique has been developed which might be a solution for the aforementioned risk-full patients. In 2004, Gagner et al. described an endoscopic procedure to restore bowel continuity after HP in a canine model. ${ }^{41}$ This procedure requires a modified HP during which the rectal stump is sutured to the sidewall of the colostomy limb in an end-to-side fashion to enable the opportunity to perform endoscopic reversal. During reversal, a rendezvous procedure is constructed during which a dedicated device is inserted through the colostomy that meets a standard circular stapler introduced through the anus. This procedure has several theoretical advantages. For one, it may eliminate the requirement for general anesthesia and associated morbidity (cardiopulmonary stress, gastrointestinal ileus). Secondly, by avoiding laparotomy or laparoscopy, the risk of postoperative associated complications may be reduced and patients may have shorter recovery time. Thirdly, this technique may be able to 
reduce the long time interval between HP and reversal found in this review consisting of approximately 7.5 months. There are certain considerations which must be taken into account. The modified HP may be more difficult in patients who are left with a short rectal stump. In addition, mobilization of the splenic flexure may be necessary which, however, creates an additional risk for complications (3.1\%). Furthermore, until now, during endoscopic reversal, the final anastomosis is made without direct visualization of the circular anastomosis.

A comparable endoscopic technique has been performed in 13 patients by Vermeulen et al. Essentially, HR was performed through the stomal opening. Through an incision at the formal stoma side, lysis of intra-abdominal adhesions could be performed manually. The rectal stump was identified intra-abdominally using a transanal club, and an end-to-end colorectal anastomosis was created under manual control. There were two conversions due to strong adhesions in the lower pelvic cavity, and no complications occurred. Unfortunately, as in the technique described by Jacob et al., the anastomosis was made without direct visualization. In the future, an adjusted stapler with a fiber optic viewing channel might overcome this problem.

In conclusion, based on the published literature, reversal of the Hartmann procedure carries a high operative morbidity and mortality and is performed in only $44 \%$ of patients. Principally, relatively younger and healthy patients are eligible for reversal. This leaves a considerable group of patients, mainly older with poor health condition, with a permanent stoma. Laparoscopic reversal compares favorably to conventional; however, high level evidence is needed to determine whether it is superior. Endoscopic techniques might be upcoming and may introduce the possibility for the older and fragile patients to undergo reversal.

Open Access This article is distributed under the terms of the Creative Commons Attribution Noncommercial License which permits any noncommercial use, distribution, and reproduction in any medium, provided the original author(s) and source are credited.
Table 5 Time Interval Between HP-HR and Mortality During This Interval

\begin{tabular}{|c|c|c|c|}
\hline First author (year) & $\begin{array}{l}\text { Interval between HP and } \\
\text { conventional HR ( } n \text { months) }\end{array}$ & $\begin{array}{l}\text { Interval between HP and } \\
\text { laparoscopic HR ( } n \text { months) }\end{array}$ & $\begin{array}{l}\text { Mortality in } \\
\text { time interval }(\%)\end{array}$ \\
\hline Sweeney (1987) & 5.6 & - & - \\
\hline Geoghegan (1991) & 6.5 & - & - \\
\hline Roe (1991) & 4.5 & - & - \\
\hline Pearce (1992) & 6 & - & - \\
\hline Keck (1993) & 8.5 & - & - \\
\hline Khan (1994) & $3-6$ & - & - \\
\hline Wigmore (1995) & $0-3$ & - & - \\
\hline Carcoforo (1996) & 7.7 & - & - \\
\hline Macpherson (1996) & - & 7.5 & - \\
\hline Seetharam (2003) & 7.6 & - & 19 \\
\hline Banerjee (2004) & 8.3 & - & 16 \\
\hline Maggard (2004) & 5 & - & - \\
\hline Salem (2004) & 5 & - & - \\
\hline Bell (2005) & 10.6 & & - \\
\hline Boland (2007) & 11.5 & - & - \\
\hline Schmelzer (2007) & 10.2 & - & - \\
\hline Roque (2007) & 13.3 & - & - \\
\hline Faure (2007) & 4 & 6 & - \\
\hline Leong (2008) & 9 & - & 7 \\
\hline Haughn (2008) & 14 & 5.7 & - \\
\hline Vermeulen (2008) & 9.1 & - & - \\
\hline Chouillard (2008) & 5.1 & 6.2 & - \\
\hline Carus (2008) & - & 2.5 & - \\
\hline Mazeh (2009) & 7.7 & 4.9 & - \\
\hline David (2009) & 9.5 & - & - \\
\hline Mean & 8.0 & 5.5 & 14 \\
\hline
\end{tabular}




\section{References}

1. Roque-Castellano C, Marchena-Gomez J, Hemmersbach-Miller M, Acosta-Merida A, Rodriguez-Mendez A, Farina-Castro R, et al. Analysis of the factors related to the decision of restoring intestinal continuity after Hartmann's procedure. Int J Colorectal Dis 2007;22 (9):1091-1096.

2. Bell C, Asolati M, Hamilton E, Fleming J, Nwariaku F, Sarosi G, et al. A comparison of complications associated with colostomy reversal versus ileostomy reversal. Am J Surg 2005;190(5):717-720.

3. Vermeulen J, Coene PP, Van Hout NM, van der Harst E, Gosselink MP, Mannaerts GH, et al. Restoration of bowel continuity after surgery for acute perforated diverticulitis: should Hartmann's procedure be considered a one-stage procedure? Colorectal Dis 2008;11:619-624.

4. Carcoforo P, Navarra G, Di Marco L, Occhionorelli S, Rocca T, Pollinzi V. Reversal of Hartmann's procedure. Our experience. Ann Ital Chir 1997;68(4):523-527. discussion 527-8.

5. Geoghegan JG, Rosenberg IL. Experience with early anastomosis after the Hartmann procedure. Ann R Coll Surg Engl 1991;73 (2):80-82.

6. Sweeney JL, Hoffmann DC. Restoration of continuity after Hartmann's procedure for the complications of diverticular disease. Aust N Z J Surg 1987;57(11):823-825.

7. Basse L, Jacobsen DH, Billesbolle P, Kehlet H. Colostomy closure after Hartmann's procedure with fast-track rehabilitation. Dis Colon Rectum 2002;45(12):1661-1664.

8. Roe AM, Prabhu S, Ali A, Brown C, Brodribb AJ. Reversal of Hartmann's procedure: timing and operative technique. Br J Surg 1991;78(10):1167-1170.

9. Pearce NW, Scott SD, Karran SJ. Timing and method of reversal of Hartmann's procedure. Br J Surg 1992;79(8):839-841.

10. Keck JO, Collopy BT, Ryan PJ, Fink R, Mackay JR, Woods RJ. Reversal of Hartmann's procedure: effect of timing and technique on ease and safety. Dis Colon Rectum 1994;37(3):243-248.

11. Sosa JL, Sleeman D, Puente I, McKenney MG, Hartmann R. Laparoscopic-assisted colostomy closure after Hartmann's procedure. Dis Colon Rectum 1994;37(2):149-152.

12. Khan AL, Ah-See AK, Crofts TJ, Heys SD, Eremin O. Reversal of Hartmann's colostomy. J R Coll Surg Edinb 1994;39(4):239-242.

13. Wigmore SJ, Duthie GS, Young IE, Spalding EM, Rainey JB. Restoration of intestinal continuity following Hartmann's procedure: the Lothian experience 1987-1992. Br J Surg 1995;82 (1):27-30

14. Macpherson SC, Hansell DT, Porteous C. Laparoscopic-assisted reversal of Hartmann's procedure: a simplified technique and audit of twelve cases. J Laparoendosc Surg 1996;6(5):305-310.

15. Regadas FS, Siebra JA, Rodrigues LV, Nicodemo AM, Reis Neto JA. Laparoscopically assisted colorectal anastomose postHartmann's procedure. Surg Laparosc Endosc 1996;6(1):1-4.

16. Seetharam S, Paige J, Horgan PG. Impact of socioeconomic deprivation and primary pathology on rate of reversal of Hartmann's procedure. Am J Surg 2003;186(2):154-157.

17. Maggard MA, Zingmond D, O'Connell JB, Ko CY. What proportion of patients with an ostomy (for diverticulitis) get reversed? Am Surg 2004;70(10):928-331.

18. Banerjee S, Leather AJ, Rennie JA, Samano N, Gonzalez JG, Papagrigoriadis S. Feasibility and morbidity of reversal of Hartmann's. Colorectal Dis 2005;7(5):454-459.

19. Rosen MJ, Cobb WS, Kercher KW, Sing RF, Heniford BT. Laparoscopic restoration of intestinal continuity after Hartmann's procedure. Am J Surg 2005;189(6):670-674.

20. Albarran SA, Simoens C, Takeh H, Mendes da Costa P. Restoration of digestive continuity after Hartmann's procedure. Hepatogastroenterology 2004;51(58):1045-1049.
21. Aydin HN, Remzi FH, Tekkis PP, Fazio VW. Hartmann's reversal is associated with high postoperative adverse events. Dis Colon Rectum 2005;48(11):2117-2126.

22. Khaikin M. Laparoscopically assisted reversal of Hartmann's procedure. Surg Endosc 2007;21(7):1256.

23. Salem L, Flum DR. Primary anastomosis or Hartmann's procedure for patients with diverticular peritonitis? A systematic review. Dis Colon Rectum 2004;47(11):1953-1964.

24. Oomen JL, Cuesta MA, Engel AF. Reversal of Hartmann's procedure after surgery for complications of diverticular disease of the sigmoid colon is safe and possible in most patients. Dig Surg 2005;22(6):419-425.

25. Faure JP, Doucet C, Essique D, Badra Y, Carretier M, Richer JP, et al. Comparison of conventional and laparoscopic Hartmann's procedure reversal. Surg Laparosc Endosc Percutan Tech 2007;17(6):495-499.

26. Boland E, Hsu A, Brand MI, Saclarides TJ. Hartmann's colostomy reversal: outcome of patients undergoing surgery with the intention of eliminating fecal diversion. Am Surg 2007;73 (7):664-667. discussion 668 .

27. Schmelzer TM, Mostafa G, Norton HJ, Newcomb WL, Hope WW, Lincourt AE, et al. Reversal of Hartmann's procedure: a high-risk operation? Surgery 2007;142(4):598-606. discussion 606-7.

28. Carus T, Bollmann S, Lienhard H. Laparoscopic reversal of Hartmann's procedure: technique and results. Surg Laparosc Endosc Percutan Tech 2008;18(1):24-28.

29. Haughn C, Ju B, Uchal M, Arnaud JP, Reed JF, Bergamaschi R. Complication rates after Hartmann's reversal: open vs. laparoscopic approach. Dis Colon Rectum 2008;51(8):1232-1236.

30. Slawik S, Dixon AR. Laparoscopic reversal of Hartmann's rectosigmoidectomy. Colorectal Dis 2008;10(1):81-83.

31. Chouillard E, Pierard T, Campbell R, Tabary N. Laparoscopically assisted Hartmann's reversal is an efficacious and efficient procedure: a case control study. Minerva Chir 2008;64:1-8.

32. Mazeh H, Greenstein AJ, Swedish K, Nguyen SQ, Lipskar A, Weber $\mathrm{KJ}$, et al. Laparoscopic and open reversal of Hartmann's procedure - a comparative retrospective analysis. Surg Endosc 2009;23(3):496-502.

33. Leong QM, Koh DC, Ho CK. Emergency Hartmann's procedure: morbidity, mortality and reversal rates among Asians. Tech Coloproctol 2008;12(1):21-25.

34. Petersen M, Kockerling F, Lippert H, Scheidbach H. Laparoscopically assisted reversal of Hartmann procedure. Surg Laparosc Endosc Percutan Tech 2009;19(1):48-51.

35. David GG, Al-Sarira AA, Willmott S, Cade D, Corless DJ, Slavin JP. Use of Hartmann's procedure in England. Colorectal Dis 2009;11(3):308-312.

36. Abbas S. Resection and primary anastomosis in acute complicated diverticulitis, a systematic review of the literature. Int J Colorectal Dis 2007:22(4):351-357.

37. Tilney HS, Sains PS, Lovegrove RE, Reese GE, Heriot AG, Tekkis PP. Comparison of outcomes following ileostomy versus colostomy for defunctioning colorectal anastomoses. World J Surg 2007;31(5):1142-1151.

38. Rullier E, Le Toux N, Laurent C, Garrelon JL, Parneix M, Saric J. Loop ileostomy versus loop colostomy for defunctioning low anastomoses during rectal cancer surgery. World J Surg 2001;25 (3):274-277. discussion 277-8.

39. Edwards DP, Leppington-Clarke A, Sexton R, Heald RJ, Moran BJ. Stoma-related complications are more frequent after transverse colostomy than loop ileostomy: a prospective randomized clinical trial. Br J Surg 2001;88(3):360-363.

40. Gastinger I, Marusch F, Steinert R, Wolff S, Koeckerling F, Lippert $\mathrm{H}$, et al. Protective defunctioning stoma in low anterior resection for rectal carcinoma. Br J Surg 2005;92(9):1137-42.

41. Jacob BP, Gagner M, Hung TI, Fukuyama S, Waage A, Biertho L, et al. Dual endoscopic-assisted endoluminal colostomy reversal: a feasibility study. Surg Endosc 2004;18(3):433-9. 